\title{
Development of dual inhibitors targeting DprE1 and AHAS for treatment of Mycobacterium tuberculosis infection
}

\author{
Rupesh V Chikhale*, Amit M Pant, Sunil S Menghani, Pramod B Khedekar \\ From 2nd International Science Symposium on HIV and Infectious Diseases (HIV SCIENCE 2014) \\ Chennai, India. 30 January - 1 February 2014
}

\section{Background}

The emerging multidrug resistant (MDR) and extensively drug resistant (XDR) Mycobacterium tuberculosis (MTB) infection is increasing with greater complexity, estimated 220000-400000 tuberculosis cases emerged in 2011 globally. A number of lead compounds have been developed for treatment of MDR and XDR TB, but no new chemical entity has emerged for clinical use. Recently DprE1 and AHAS have been identified as promising drug targets.

\section{Methods}

The methodology involved in silico studies, synthesis and in vitro evaluation for inhibition of $M$. tuberculosis. In silico studies involved protein preparation for DprE1, AHAS, docking and analysis of docking results. Sixty two substituted (thiazolidine-2-yl amino) benzthiazolylphenylhydrazine carbothiamide derivatives were studied. In vitro evaluation was carried out by modified agar diffusion method.

\section{Results}

About 62 compounds were synthesized based on molecular docking studies. In case of DprE1 maximum interactions were found with His132, Asn385, Gly133, Leu134, Leu363, Val365, whereas in case of AHAS maximum interactions were shown between Arg318, Gly138, Lys197, Trp516 and Phe147. All compounds were synthesized in satisfactory yield and structurally elucidated. The range of MIC was found between $40-80 \mathrm{mg} / \mathrm{L}$ with percentage inhibition in range of $80-95 \%$.

\section{Conclusion}

Experimental results reveales that newly developed compounds exhibited promising antitubercular activity which can be further explored for development of potent drugs.

Published: 27 May 2014

doi:10.1186/1471-2334-14-S3-E24

Cite this article as: Chikhale et al:: Development of dual inhibitors targeting DprE1 and AHAS for treatment of Mycobacterium tuberculosis infection. BMC Infectious Diseases 2014 14(Suppl 3):E24.

* Correspondence: rupeshchikhale7@gmail.com

Department of Pharmaceutical Sciences, Rashtrasant Tukadoji Maharaj Nagpur University, Nagpur, India

Submit your next manuscript to BioMed Central and take full advantage of:

- Convenient online submission

- Thorough peer review

- No space constraints or color figure charges

- Immediate publication on acceptance

- Inclusion in PubMed, CAS, Scopus and Google Scholar

- Research which is freely available for redistribution
C Biomed Central 